Check for updates

Cite this: RSC Adv., 2020, 10, 41802

Received 14th October 2020

Accepted 10th November 2020

DOI: $10.1039 / \mathrm{dOra0} 8758 \mathrm{k}$

rsc.li/rsc-advances

\section{Stereocontrolled addition of Grignard reagents to oxa-bridged benzazepines: highly efficient synthesis of functionalized benzazepine scaffolds $\uparrow$}

\author{
Yuewei Zhang, (D) Qingqing Bao, Ning Zhang, Shuohang Wang and Xue Yu* \\ An efficient and highly diastereoselective synthesis of 2-substituted benzo[b]azepin-5-ol via \\ stereocontrolled addition of Grignard reagents to oxa-bridged benzazepines has been developed. The \\ reaction proceeds efficiently starting from versatile skeletons with mild reaction conditions as well as \\ simple operation. Furthermore, 2-substituted benzazepinones could been obtained by simple Dess- \\ Martin oxidation in excellent yields.
}

Benzofused azepines, a unique family of seven-member azaheterocycles, are widely found in numerous bioactive molecules, natural products and pharmaceuticals. ${ }^{1-4}$ This is due to their chemotherapeutic properties, and exhibiting interesting biological activities, ${ }^{5-9}$ for instance, competitive vasopressin receptor antagonist (tolvaptan), ${ }^{\mathbf{1 0}-12}$ antidepressants (mianserin), ${ }^{13}$ zilpaterol (beef improvement agent) ${ }^{14}$ ACE inhibitor (benazepril) ${ }^{15}$ (Fig. 1).

Consequently, tremendous efforts have recently been dedicated to developing new methodologies to construct the benzazepine derivatives. Typically, the benzazepine skeletons could be assembled by expansion of smaller rings, rearrangements, ${ }^{16,17}$ Dieckmann cyclization, ${ }^{18,19}$ transition-metal-catalyzed coupling, ring closure metathesis, ${ }^{15,20,21}$ and others. ${ }^{22-25}$ Nevertheless, most of these protocols are limited to highly engineered starting materials, expensive catalysts and hazardous handling, obviously expeditious strategies for the diverse construction of benzazepine backbones from readily available starting materials, remains highly attractive and challenging.

Diversity-oriented synthesis (DOS), defined as a powerful synthetic strategy to the libraries of diverse highly valuable molecules from one parent compound, ${ }^{26,27}$ is therefore wellsuited for the timely design and execution of parallel (library) synthesis. ${ }^{28}$ In recent years, our group focused on the development of a more facile and efficient diversity-oriented synthesis strategy for the generation of this class of 7-membered heterocyclic compounds. ${ }^{29-31}$ This newly introduced ene-type cyclization reaction was used to prepare a series of bridged aromatic fused azepines, ${ }^{29}$ as a versatile building block, which could be

School of Chemistry and Pharmaceutical Engineering, Jilin Institute of Chemical Technology, Jilin 132022, China. E-mail: dongjibinghuayuxue@163.com

$\dagger$ Electronic supplementary information (ESI) available. CCDC 1033762. For ESI and crystallographic data in CIF or other electronic format see DOI: 10.1039/d0ra08758k transformed into structurally different ring systems through selective ring opening of the cyclic acetals (Scheme 1A). ${ }^{30,31}$

As an extension of our ongoing work toward the synthesis of the azepine skeleton, we suggested a new reaction model could be achieved if the suitable nucleophile could be carefully

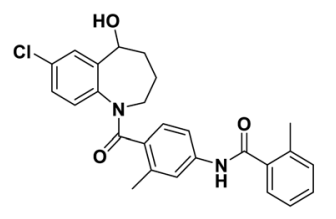

A, Tolvaptan

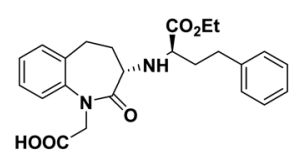

C, Benazepril

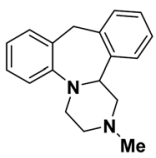

B, Mianserin

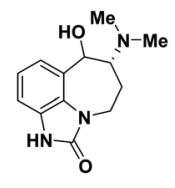

D, Zilpaterol
Fig. 1 Selected examples containing a benzazepine skeleton.

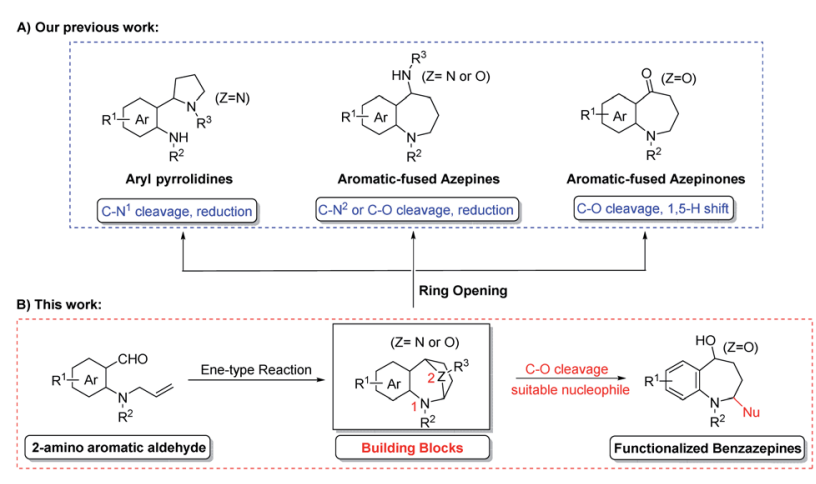

Scheme 1 Our previous work (A) and this work (B). 
designed. Recently, a couple of efficient approaches to access nitrogen-containing heterocycles has been developed through the nucleophilic addition of cyclic $\mathrm{N}, \mathrm{O}$-acetal with Grignard reagents. ${ }^{32-35}$ Inspired by their excellent studies and to showcase the utility of cyclic $\mathrm{N}, \mathrm{O}$-acetal building blocks for the preparation of functionalized azepines, we present a facile approach to a stereoselective synthesis of 2,5-substituted benzazepine derivatives from oxa-bridged benzazepines by Grignard addition. This strategy is complementary to our recently published cascade reaction to prepare the benzazepinone scaffold. Herein, the details of this study is disclosed.

Our investigations commenced by exploring nucleophilic addition of 1a, which was readily prepared in two steps via substitution reaction and subsequent ene-type reaction (see the ESI $\dagger$ ). We started our screening with 1-allyl-2,3,4,5-tetrahydro$1 H$-2,5-epoxybenzo[ $b]$ azepine (1a) as a model substrate for the optimization of the reaction conditions (Table 1). First, we chose the commonly used solvent tetrahydrofuran and dioxane for Grignard addition, no 2a was observed (Table 1, entries 1 and 2). The desired product 2a was obtained in 92\% yield, along with low diastereoselectivity ( $d r=24: 76)$, when the reaction was carried out in diethyl ether (Table 1, entry 3 ). Subsequently, we conducted this nucleophilic addition of $\mathbf{1 a}$ in halogen-containing solvent instead of the more commonly used ether solvent to increase the coordination of organomagnesium to the substrates. ${ }^{36,37}$ We were gratified to find that Grignard reagents could indeed be added with high selectivity (Table 1, entries 4-6).

However, there was no significant improvement in the diastereoselectivity was observed after the addition of magnesium bromide $^{36}$ (Table 1, entry 7). The experimental results show that the ring-opening reaction of $N, O$ acetals were sensitive to size of substituent $\mathrm{R}^{1}$, and the syn-selectivity became better as the size of Grignard reagents increased (Table 1, entries 8, 9).
After establishing the optimized reaction conditions, we investigated the addition of Grignard reagents to a series of oxabridged azepine $\mathbf{1}$, and the results are listed in Table 2 . We were pleased to observe that this reaction exhibited broad substrate scope, and the aliphatic and aromatic Grignard reagents reacted smoothly with 1a. These reactions generated aminoalcohols

Table 2 Nucleophilic addition with Grignard reagents on cyclic N,Oacetals $^{a}$

\begin{tabular}{|c|c|c|c|c|c|c|c|c|}
\hline & ${ }_{1}^{\mathrm{R}^{3}}$ & $\frac{\mathrm{R}^{1} \mathrm{M}}{\mathrm{CH}_{2} \mathrm{C}}$ & $\begin{array}{l}\mathrm{Br} \\
2,0^{\circ} \mathrm{C}\end{array}$ & & $\begin{array}{r}\mathrm{R}^{3} \\
\text { syn-2 }\end{array}$ & & & $\begin{array}{c}\mathrm{R}^{3} \\
\text { anti-2 }\end{array}$ \\
\hline Entry & $\mathrm{N}, \mathrm{O}$-Acetals & $\mathrm{R}^{1}$ & $\mathrm{R}^{2}$ & $\mathrm{R}^{3}$ & Time & 2 & Yield (\%) & syn/anti ${ }^{b}$ \\
\hline 1 & $1 \mathrm{a}$ & $\mathrm{Me}$ & $\mathrm{H}$ & Allyl & $10 \mathrm{~min}$ & $2 a$ & 96 & $69 / 31$ \\
\hline 2 & $1 a$ & Et & $\mathrm{H}$ & Allyl & $10 \mathrm{~min}$ & $2 \mathbf{b}$ & 97 & $91 / 9$ \\
\hline 3 & $1 \mathrm{a}$ & $i$-Pr & $\mathrm{H}$ & Allyl & $7 \mathrm{~h}$ & $2 c$ & 88 & $100 / 0$ \\
\hline 4 & $1 \mathrm{a}$ & Cy & $\mathrm{H}$ & Allyl & $18 \mathrm{~h}$ & $2 d$ & 83 & $100 / 0$ \\
\hline 5 & $1 \mathrm{a}$ & Allyl & $\mathrm{H}$ & Allyl & $10 \mathrm{~min}$ & $2 e$ & 98 & $0 / 100$ \\
\hline 6 & $1 \mathrm{a}$ & $\mathrm{Ph}$ & $\mathrm{H}$ & Allyl & $10 \mathrm{~min}$ & 2f & 98 & $100 / 0$ \\
\hline 7 & $1 b$ & $\mathrm{Me}$ & $\mathrm{Me}$ & Allyl & $10 \mathrm{~min}$ & $2 \mathrm{~g}$ & 91 & $88 / 12$ \\
\hline 8 & $1 b$ & Allyl & $\mathrm{Me}$ & Allyl & $10 \mathrm{~min}$ & $2 h$ & 90 & $0 / 100$ \\
\hline 9 & $1 \mathrm{c}$ & $\mathrm{Me}$ & $\mathrm{Cl}$ & Allyl & $10 \mathrm{~min}$ & $2 \mathbf{i}$ & 92 & $67 / 33$ \\
\hline 10 & $1 \mathrm{c}$ & Allyl & $\mathrm{Cl}$ & Allyl & $10 \mathrm{~min}$ & $2 j$ & 91 & $0 / 100$ \\
\hline 11 & 1d & $\mathrm{Me}$ & $\mathrm{H}$ & $\mathrm{Me}$ & $10 \mathrm{~min}$ & $2 k$ & 92 & $68 / 32$ \\
\hline 12 & 1d & $i$-Pr & $\mathrm{H}$ & $\mathrm{Me}$ & $5 \mathrm{~min}$ & 21 & 91 & $100 / 0$ \\
\hline 13 & $1 e$ & $\mathrm{Me}$ & $\mathrm{H}$ & $\mathrm{H}$ & $1 \mathrm{~h}$ & $2 \mathrm{~m}$ & 80 & $91 / 9$ \\
\hline 14 & 1e & Allyl & $\mathrm{H}$ & $\mathrm{H}$ & $10 \mathrm{~min}$ & $2 n$ & 81 & $75 / 25$ \\
\hline
\end{tabular}

${ }^{a}$ Unless indicated otherwise, the reaction was carried out on $1.0 \mathrm{mmol}$ scale in DCM $(10 \mathrm{~mL}) .{ }^{b}$ Diastereoisomeric ratios were determined by ${ }^{1} \mathrm{H}$ NMR analysis of the mixture, see the ESI for details.

Table 1 Optimization of the Grignard addition conditions ${ }^{a}$

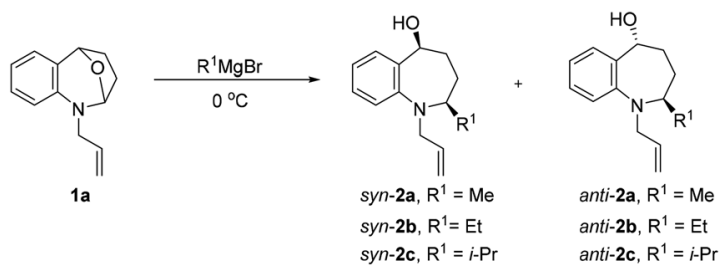

\begin{tabular}{|c|c|c|c|c|c|}
\hline Entry & Solvent & Additive & Time & Yield $^{b}(\%)$ & $d r(\text { syn/anti })^{c}$ \\
\hline $1^{d}$ & THF & - & $10 \mathrm{~h}$ & 0 & - \\
\hline $2^{d}$ & Dioxane & - & $10 \mathrm{~h}$ & 0 & - \\
\hline 4 & 1,2-Dichloroethane & - & $10 \mathrm{~min}$ & 90 & $2 a, 68 / 32$ \\
\hline 5 & $\mathrm{CHCl}_{3}$ & - & $10 \mathrm{~min}$ & 95 & $2 a, 66 / 34$ \\
\hline 6 & $\mathrm{CH}_{2} \mathrm{Cl}_{2}$ & - & $10 \mathrm{~min}$ & 96 & $2 a, 69 / 31$ \\
\hline 9 & $\mathrm{CH}_{2} \mathrm{Cl}_{2}$ & - & $10 \mathrm{~min}$ & 88 & $2 c, 100 / 0$ \\
\hline
\end{tabular}

${ }^{a}$ Reaction conditions: $1 \mathrm{a}(1 \mathrm{mmol}), \mathrm{MeMgBr}$ in $10 \mathrm{~mL}$ of solvent at $0{ }^{\circ} \mathrm{C}$ under air. ${ }^{b}$ Isolated yield after column chromatography. ${ }^{c}$ Determined by

${ }^{1} \mathrm{H}$ NMR and X-ray crystallographic analysis. ${ }^{d}$ The reaction was conducted at $0{ }^{\circ} \mathrm{C}$ for $1 \mathrm{~h}$, then at $25{ }^{\circ} \mathrm{C}$ for $9 \mathrm{~h}$. 
2 in good chemical yields and with excellent selectivity and the structure of $\mathbf{2 m}$ was further confirmed by X-ray crystallography analysis. The compound $\mathbf{2 m}$ was recrystallized in an ethyl acetate/petroleum ether solution to obtain a single configuration compound syn-2m, which was tested by single crystal X-ray diffraction (Fig. 2). From the diffraction pattern, it could be clearly seen that the hydroxyl group and the methyl group are on the same side. The stereochemistry in the rest of the series could be unambiguously assigned by comparison of their NMR spectra with those of syn-2m.

In general, the improved diastereoselectivities were observed with increasing steric bulk of the Grignard reagents, the synadduct was the major product in all cases (Table 2, entries1-4). The anomalous diastereoselection shown by allyl Grignard reagent is to be underlined. Possibly this is due to the peculiar nature of allyl metals (Table 2, entries 5, 8, 10).$^{38-43}$ Even phenylmagnesium bromide could be added to $\mathbf{1 a}$ and provided the adduct in 98\% yield and a single syn-adduct (Table 2, entry 6), despite the considerably higher basicity of this Grignard reagent. ${ }^{37}$ 7-Substituented substrates $(\mathbf{1 b}, \mathbf{1 c})$ were also tolerated by this process, as well as Me at the nitrogen atom of the substrate (1d) (Table 1, entries 7-12). To further expand the scope of this reaction, $\mathrm{N}$-unsubstituted cyclic $\mathrm{N}, \mathrm{O}$-acetal $1 \mathrm{e}$ was employed under the established condition, the expected product was obtained smoothly and in good yield as well. Surprisingly, even lower proportions of syn-diastereoisomers were observed relative to methyl Grignard reagent correlated with increasing steric bulk of the Grignard reagent (Table 2, entries 13-14).

The observed diastereoselectivity for the Grignard reaction of $\mathrm{N}$-substituted cyclic $\mathrm{N}, \mathrm{O}$-acetals 1 leading to 2 can be rationalized by assuming that the Grignard reagent coordinates with the oxygen atom of the cyclic $\mathrm{N}, \mathrm{O}$-acetal ring $\mathbf{1}$ and that the subsequent intramolecular delivery of the alkyl group occurs on the same face of the $\mathrm{C}-\mathrm{O}$ bond of the incipient iminium salt $\mathbf{A}$ as shown in Fig. 3 (transition state A). ${ }^{\mathbf{3 6 , 4 4 , 4 5}}$ However, this diastereoselectivity for Grignard addition to the $N$-unsubstituted cyclic $N, O$-acetal 1a may be attributed to a highly ordered transition state resulting from significant chelation of the alkoxy substituent and imino nitrogen to at least one magnesium cation as shown Fig. 3 (transition state B). ${ }^{\mathbf{4 6 , 4 7}}$

To give the intrinsic versatility of 2 -substituted benzo[ $[b]$ azepin-5-ol and as a complement to our recently published cascade reaction to prepare the benzazepinone scaffold, treatment of the above compounds 2 with Dess-Martin in $\mathrm{CH}_{2} \mathrm{Cl}_{2}$ gave the 2-substituted benzazepinones 3 in good to excellent yields (Table 3, entries 1-10), except the $\mathbf{3 k}$ (Table 3, entry 11).

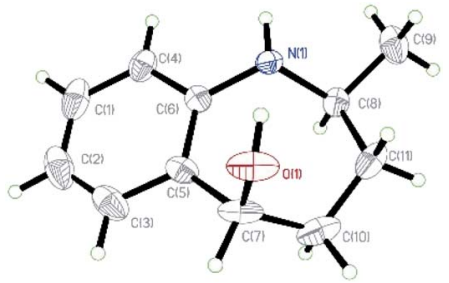

Fig. 2 X-ray crystallographic structure of syn-2m.

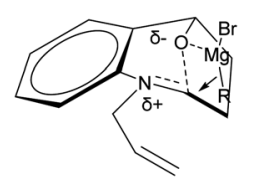

Transition State A

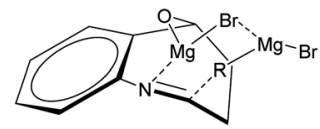

Transition State B
Fig. 3 Proposed transition states accounting for the diastereoselectivity.

The synthetic versatility of 2-substituted benzazepinones has also been explored. The fused tricyclic compound 4 (ref. 48) could also be readily synthesized from $3 \mathbf{e}$. Treatment of $3 \mathbf{e}$ with Grubbs II catalyst led to 4 in $95 \%$ yield [eqn (1)].

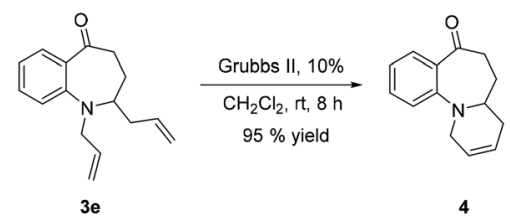

In conclusion, we have demonstrated that the cyclic $\mathrm{N}, \mathrm{O}$ acetals were successfully applied to the diastereoselective addition of various Grignard reagents with encouraging levels of stereoselection. In the formation of 2,5-substituted 1-benzazepine derivatives, the reaction proceeds through a ring-opening/nucleophilic addition pathway. These benzo $[b]$ azepin-5-ols then undergo simple Dess-Martin oxidation to afford the 2-substituted benzazepinones in excellent yields. In respect to the easy availability of the starting materials, simple manipulation, mild conditions and high diastereoselectivity, this reaction will be synthetically useful in organic chemistry.

Table 3 The synthesis of 2-substituted benzazepinones ${ }^{a}$

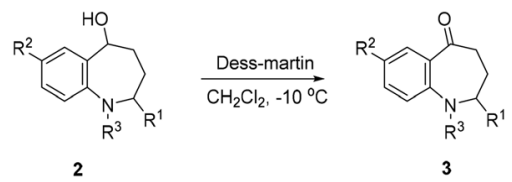

\begin{tabular}{lllllll}
\hline Entry & $\mathrm{R}^{1}$ & $\mathrm{R}^{2}$ & $\mathrm{R}^{3}$ & Time (min) & $\mathbf{3}$ & Yield (\%) \\
\hline 1 & $\mathrm{H}$ & Allyl & $\mathrm{Me}$ & 30 & $\mathbf{3 a}$ & 85 \\
2 & $\mathrm{H}$ & Allyl & Et & 30 & $\mathbf{3 b}$ & 83 \\
3 & $\mathrm{H}$ & Allyl & $i$-Pr & 15 & $\mathbf{3 c}$ & 86 \\
4 & $\mathrm{H}$ & Allyl & Cy & 15 & $\mathbf{3 d}$ & 80 \\
5 & H & Allyl & Allyl & 15 & $\mathbf{3 e}$ & 75 \\
6 & $\mathrm{H}$ & Allyl & Ph & 15 & $\mathbf{3 f}$ & 88 \\
7 & Me & Allyl & Me & 20 & $\mathbf{3 g}$ & 88 \\
8 & Me & Allyl & Allyl & 45 & $\mathbf{3 h}$ & 76 \\
9 & Cl & Allyl & Me & 60 & $\mathbf{3 i}$ & 84 \\
10 & Cl & Allyl & Allyl & 60 & $\mathbf{3 j}$ & 78 \\
11 & H & H & Me & 20 & $\mathbf{3 k}$ & 38
\end{tabular}

${ }^{a}$ Unless indicated otherwise, the reaction was carried out on $0.5 \mathrm{mmol}$ scale in DCM $(5 \mathrm{~mL})$. 


\section{Conflicts of interest}

There are no conflicts to declare.

\section{Acknowledgements}

Science and Technology Project of Jilin Provincial Department of Education (JJKH20200242KJ), Science and Technology Innovation and Development Plan Project in Jilin City (201750231, 20190104196), and Research projects in Jilin Institute of Chemical Technology (2016004, 2017007, 2017011, 2018030).

\section{Notes and references}

1 E. Vitaku, D. T. Smith and J. T. Njardarson, J. Med. Chem., 2014, 57, 10257-10274.

2 J. Benes, A. Parada, A. A. Figueiredo, P. C. Alves, A. P. Freitas, D. A. Learmonth, R. A. Cunha, J. Garrett and P. Soares-daSilva, J. Med. Chem., 1999, 42, 2582-2587.

3 A. Link and C. Kunick, J. Med. Chem., 1998, 41, 1299-1305. 4 M. Seto, N. Miyamoto, K. Aikawa, Y. Aramaki, N. Kanzaki, Y. Iizawa, M. Baba and M. Shiraishi, Bioorg. Med. Chem., 2005, 13, 363-386.

5 C. Schultz, A. Link, M. Leost, D. W. Zaharevitz, R. Gussio, E. A. Sausville, L. Meijer and C. Kunick, J. Med. Chem., 1999, 42, 2909-2919.

6 C. Kunick, K. Lauenroth, K. Wieking, X. Xie, C. Schultz, R. Gussio, D. Zaharevitz, M. Leost, L. Meijer, A. Weber, F. S. Jorgensen and T. Lemcke, J. Med. Chem., 2004, 47, 2236.

7 Z. Li, N. Lu, L. Wang and W. Zhang, Eur. J. Org. Chem., 2012, 2012, 1019-1024.

8 A. Palma, A. F. Yépes, S. M. Leal, C. A. Coronado and P. Escobar, Bioorg. Med. Chem. Lett., 2009, 19, 2360-2363.

9 S. L. Gómez Ayala, E. Stashenko, A. Palma, A. Bahsas and J. M. Amaro-Luis, Synlett, 2006, 14, 2275-2277.

10 H. Ogawa, H. Yamashita, K. Kondo, Y. Yamamura, H. Miyamoto, K. Kan, K. Kitano, M. Tanaka, K. Nakaya, S. Nakamura, T. Mori, M. Tominaga and Y. Yabuuchi, $J$. Med. Chem., 1996, 39, 3547-3555.

11 K. Kondo, H. Ogawa, T. Shinohara, M. Kurimura, Y. Tanada, K. Kan, H. Yamashita, S. Nakamura, T. Hirano, Y. Yamamura, T. Mori, M. Tominaga and A. Itai, J. Med. Chem., 2000, 43, 4388-4397.

12 K. Kondo, K. Kan, Y. Tanada, M. Bando, T. Shinohara, M. Kurimura, H. Ogawa, S. Nakamura, T. Hirano, Y. Yamamura, M. Kido, T. Mori and M. Tominaga, J. Med. Chem., 2002, 45, 3805-3808.

13 P. Roszkowski, J. K. Maurin and Z. Czarnocki, Beilstein J. Org. Chem., 2015, 11, 1509-1513.

14 C. Kern, T. Meyer, S. Droux, D. Schollmeyer and C. Miculka, J. Med. Chem., 2009, 52, 1773-1777.

15 S. Kotha and V. R. Shah, Eur. J. Org. Chem., 2008, 2008, 10541064.

16 A. Cordero-Vargas, B. Quiclet-Sire and S. Z. Zard, Bioorg. Med. Chem., 2006, 14, 6165-6173.
17 R. W. Rickards and R. M. Smith, Tetrahedron Lett., 1966, 7, 2361-2365.

18 K. Kondo, H. Ogawa, H. Yamashita, H. Miyamoto, M. Tanaka, K. Nakaya, K. Kitano, Y. Yamamura, S. Nakamura, T. Onogawa, T. Mori and M. Tominaga, Bioorg. Med. Chem., 1999, 7, 1743-1754.

19 Y. Kawakita, M. Seto, T. Ohashi, T. Tamura, T. Yusa, H. Miki, H. Iwata, H. Kamiguchi, T. Tanaka, S. Sogabe, Y. Ohta and T. Ishikawa, Bioorg. Med. Chem., 2013, 21, 2250-2261.

20 S. J. Dolman, R. R. Schrock and A. H. Hoveyda, Org. Lett., 2003, 5, 4899-4902.

21 D. Ghosh, L. Thander, S. K. Ghosh and S. K. Chattopadhyay, Synlett, 2008, 3011-3015.

22 T. Ohtani, Y. Kawano, K. Kitano, J. Matsubara, M. Komatsu, M. Uchida, F. Tabusa and Y. Nagao, Heterocycles, 2005, 66, 481-502.

23 M. Qadir, J. Cobb, P. W. Sheldrake, N. Whittall, A. J. P. White, K. K. Hii, P. N. Horton and M. B. Hursthouse, J. Org. Chem., 2005, 70, 1545-1551.

24 V. Singh and S. Batra, Eur. J. Org. Chem., 2007, 2007, 29702976.

25 H. He, W.-B. Liu, L.-X. Dai and S.-L. You, Angew. Chem., Int. Ed., 2010, 49, 1496-1499.

26 G. Z. Elek, K. Koppel, D. M. Zubrytski, N. Konrad, I. Järving, M. Lopp and D. G. Kananovich, Org. Lett., 2019, 21, 84738478.

27 T. J. Idzik, Z. M. Myk and J. G. Sośnicki, J. Org. Chem., 2019, 84, 8046-8066.

28 K. T. Mortensen, T. J. Osberger, T. A. King, H. F. Sore and D. R. Spring, Chem. Rev., 2019, 119, 10288-10317.

29 Y. Zhang, Y. Zhu, L. Zheng, L.-G. Zhuo, F. Yang, Q. Dang, Z.-X. Yu and X. Bai, Eur. J. Org. Chem., 2014, 2014, 660-669.

30 Y. Zhang, L. Zheng, F. Yang, Z. Zhang, Q. Dang and X. Bai, Tetrahedron, 2015, 71, 1930-1939.

31 Y. Zhang, F. Yang, L. Zheng, Q. Dang and X. Bai, Org. Lett., 2014, 16, 6041-6043.

32 Y.-Y. Huang, C. Cai, X. Yang, Z.-C. Lv and U. Schneider, ACS Catal., 2016, 6, 5747-5763.

33 H.-J. Rong, J.-J. Yao, J.-K. Li and J. Qu, J. Org. Chem., 2017, 82, 5557-5565.

34 X.-M. Wang, Y.-W. Liu, R.-J. Ma, C.-M. Si and B.-G. Wei, J. Org. Chem., 2019, 84, 11261-11267.

35 W.-L. Chen, L.-Y. Wang and Y.-J. Li, Eur. J. Org. Chem., 2020, 2020, 103-107.

36 D. M. Spero and S. R. Kapadia, J. Org. Chem., 1997, 62, 55375541.

37 A. G. Steinig and D. M. Spero, J. Org. Chem., 1999, 64, 24062410.

38 Y. Yamamoto and N. Asao, Chem. Rev., 1993, 93, 2207-2293. 39 H. Nakamura, H. Iwama and Y. Yamamoto, J. Am. Chem. Soc., 1996, 118, 6641-6647.

40 M. Nakamura, A. Hirai and E. Nakamura, J. Am. Chem. Soc., 1996, 118, 8489-8490.

41 R. Bloch, Chem. Rev., 1998, 98, 1407-1438.

42 M. Bonanni, M. Marradi, S. Cicchi, C. Faggi and A. Goti, Org. Lett., 2004, 7, 319-322. 
43 S. D. Kuduk, R. M. DiPardo, R. K. Chang, C. Ng and M. G. Bock, Tetrahedron Lett., 2004, 45, 6641-6643.

44 K. Higashiyama, H. Inoue and H. Takahashi, Tetrahedron, 1994, 50, 1083-1092.

45 C. Andrés, J. Nieto, R. Pedrosa and N. Villamañán, J. Org. Chem., 1996, 61, 4130-4135.
46 M. J. Wu and L. N. Pridgen, J. Org. Chem., 1991, 56, 13401344.

47 S. L. a. V. J. Ulrich Veith, Chem. Commun., 1996, 329-330. 48 W. H. Pearson and W.-k. Fang, J. Org. Chem., 2000, 65, 71587174. 